\title{
Innovative Timber Construction: Sustainability and Gigh Performance Building Skin
}

\author{
Fabiana Cambiaso and Matteo Varioli Pietrasanta
}

\begin{abstract}
What placement is the more suitable nowadays for a traditional material such as wood? Can it stand a chance against the wide range of hi-tech products that industrial research creates at the cost of large investments? In the current global financial crisis, wooden constructions are quickly gaining reputation not only for their reliability. An increased ecological awareness and environmental concern is the main reason for this growing trend but, aside that, we have also the perception of quality given by embedded technologies typical of this type of buildings.

Use of low emission materials and energy efficiency are no more optional requirements and wooden technology can offer them both at a fraction of the price. Greater use of wood in construction can reduce greenhouse gas emissions by stimulating the expansion of forests and by reducing requirements for fossil fuel-intensive products. Wood plays a major role in combating climate change. Trees reduce $\mathrm{CO2}$ in the atmosphere, since one cubic meter of wood absorbs around one ton of $\mathrm{CO2}$.

The purpose of this paper is to look at the appropriate tools and concepts involving timber constructions, materials, components and technologies used in several types of low energy buildings. Moreover, this paper will highlight the main application areas of interest, the current state of research and future perspectives.
\end{abstract}

Index Terms-Architectural integration, energy saving, flexibility, lightness, prefabricated elements, renewable sources.

\section{INTRODUCTION}

Today, rapidly growing economies are faced with a number of challenges around the world. The global shortage of resources such as energy and base materials as well as the ongoing urbanization and, as a result, the reduction of available space for a growing population are becoming major issues for societies. Therefore, construction techniques that save natural resources like energy, land and construction materials have become a critical factor. Wood is an extraordinary natural resource. It provides a high-performance building material without depleting the earth's resources. On average, trees absorb one ton of $\mathrm{CO} 2$ and release almost three-quarters of a ton of oxygen for every cubic meter growth. The $\mathrm{CO} 2$ is stored in the wood as carbon. Young, active trees replace the mature trees, absorbing yet more $\mathrm{CO} 2$. Further $\mathrm{CO} 2$ gains can be achieved by extending

Manuscript received May 25, 2013; revised July 10, 2013

Fabiana Cambiaso is with DATA (Design, Architectural Technology, Territory and Environment) Department, Faculty of Architecture, Sapienza University, Rome (e-mail: fabiana.cambiaso@me.com).

Matteo Varioli Pietrasanta is with Pagano (Pagano Engineering, Wood Prefabricated System), Rome (e-mail: matteo.varioli@pagano.it). the life of the wood product, by recycling into panel products, and by recovering the energy in the wood at the end of its life by using it as a biomass fuel. Managing a forest sustainably means ensuring new trees replace the harvested trees. This means the wood can be described as 'carbon negative' - it stores more carbon than the equivalent $\mathrm{CO} 2$ it emits from the harvesting, processing, transport and fabrication (Fig. 1).

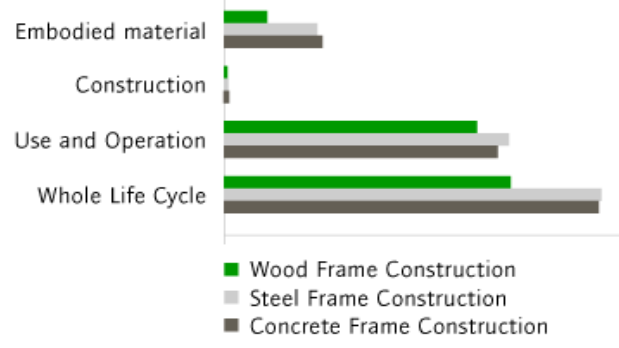

Fig. 1. The comparison of energy consumption for each phase and life cycle of three types of building: wood frame, steel frame and concrete frame construction.

The wood, traditional material par excellence and one of the oldest used in construction, offers an unparalleled versatility among other materials. It can be used in all weather conditions and at all latitudes, borrowing its properties to cover multiple functions in the building from structural elements to exterior and interior finishing. It offers solutions both for external and internal cladding, in new buildings and renovation (Fig. 2). Global wood consumption has risen along with research and experimentation over the last few years have enabling, thanks to product developments (such as wood composites), to design and manufacture buildings with performance otherwise reachable only with high costs of construction and maintenance.

Matteo Varioli Pietrasanta is with Pagano (Pagano Engineering, Wood Prefabricated System), Rome (e-mail: matteo.varioli@pagano.it).

Moreover, the environmental issue and the enactment in 2005 of the commitments made under the Kyoto Protocol on climate change, addressed to research technical and technological solutions, in particular in the field of envelope and buildings systems aimed at energy saving, providing crucial momentum to its use for the promotion of sustainable design. The framework is outlined in Directive 2010/31/EU on energy performance in buildings. Since the buildings are responsible for $40 \%$ of global energy consumption Europe aims for a significant rise in their energy efficiency and to achieve the best cost-benefit ratio. By 2020, all new buildings should be almost Net Zero Energy, 2018 for public buildings. In Europe it was decided that "the use of wood in construction and products derived therefrom should be encouraged, by 
virtue of this material to absorb carbon (Fig. 3; Fig. 4)." In most European countries were long ago incorporated the principles of sustainable forest management [1].

Among the countless technological wood properties in relation to energy efficiency, with regard to the envelope system, should be mentioned: the high resistance to weight; good machinability; low heat conductivity; high thermal storage properties; high hygroscopicity; ability to use woody species with high resistance outdoors without cladding [2].

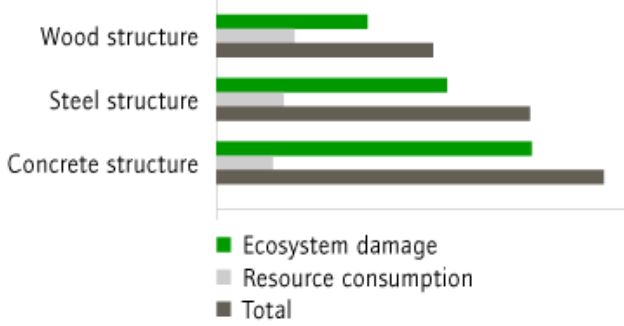

Fig. 2. Comparison of ecosystem damage and resource consumption produced by wooden, steel and concrete structures.

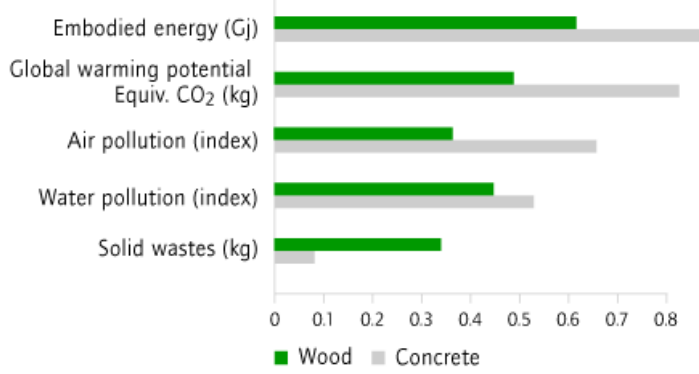

Fig. 3. Environmental impacts of wood building vs steel building. It grows in forests and plantations which clean the air, creating the conditions that make the planet habitable, while providing a natural habitat for leisure and wildlife.

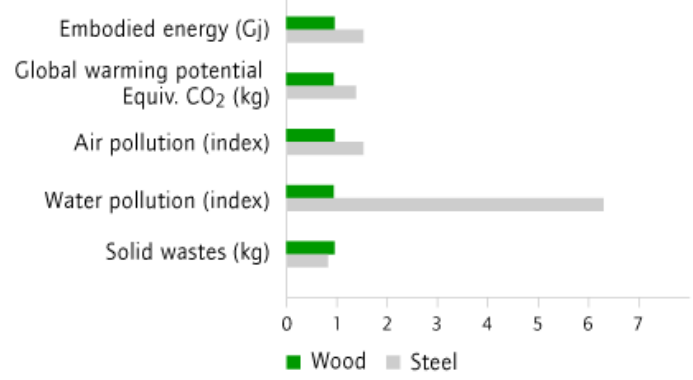

Fig. 4. Environmental impacts of wood building vs concrete building. This helps reduce the growth of $\mathrm{CO} 2$ in the atmosphere, slowing down climate change. Substituting a cubic meter of wood for other construction materials (concrete, blocks or bricks) results in an average saving of 0,7 to 1,1 ton of $\mathrm{CO} 2$.

\section{THE BUILDING WOODEN ENVELOPE}

Using exterior composite wall and roof systems, a light-weight solution, saves all of the mentioned resources. It creates an envelope which forms a highly efficient thermal insulation around a building and saves $2 / 3$ rds of the energy required for heating and cooling. But not only that. When the attic is built with exterior wall and roof panels, it allows for an additional, fully habitable floor and therefore saves some $10 \%$ of land. Also, the light-weight composite systems save other valuable resources like bricks, steel and cement. Building with prefabricated or on-site manufactured wall and roof panels results in many advantages. This technique, composite panels for exterior walls and roofs, the building envelope will not only result in more living space compared to brick walls, but also in the optimum room climate possible. In the hot season, indoor temperatures will, thanks to the higher insulation factor, stay relatively low. Whereas in the cold season, the better thermal insulation will keep rooms warm and cozy, keeping energy consumption very low. This is another reason, why this technique has been so successful in Europe for over 40 years where the extreme temperature changes required roofs and walls with optimum thermal properties (Fig. 5). The wood frame composite was the ideal solution [3], [4].

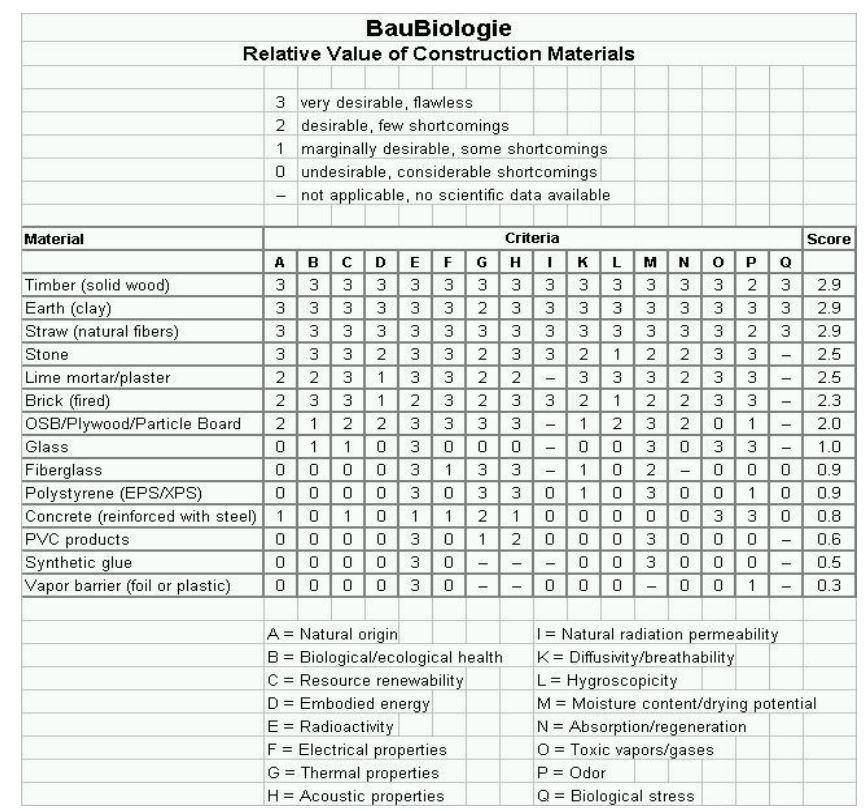

Fig. 5. Value of Construction materials. Much of the criteria and values used in the verification testing sections of the Healthy Home Standard were taken from the Supplement to the Standard of Building Biology Testing Methods SBM-2008, Building Biology Evaluation Guidelines (Bau-biologie Institute Research).

Why a durable high-performance wood building envelope adds value?

- Durable envelope design delivers the benefits of lower operation costs and a healthier building. Good design will ensure that wood materials last and weather well in various climates and physical contexts. Strategies may include minimizing contact of moisture with untreated wood, allowing for ventilation to both sides of untreated wood and designing structures to shed water.

- Planning for maintenance, deconstruction, and adaptability can extend the life of building components and of the building as a whole. Designing with wood allows for the use of easily demountable components and connections, and for the use of fasteners that ease deconstruction, facilitate maintenance, and increase the potential future reuse of building materials and components (Fig. 6 and Fig. 7). In addition, the incorporation of easily accessible systems (such as removable panels, etc.) reduces the need for extensive renovations or even replacement in the future [5].

- In general, as durability performance increases, so do the environmental merits of the project as a whole. A durable 
assembly can dramatically reduce energy consumption because the elements providing thermal performance are protected and maintain their functionality over the life of the building.Utilizing energy modeling software that incorporates building envelope performance criteria such as insulative value and air tightness will help designers to better understand the impacts of material choices - particularly the use of wood, in accomplishing an energy-efficient, durable envelope.

- Indoor air quality can also be improved by using durable materials that have zero or low emissions and that prevent moisture accumulation and mould or mildew growth.

- Durable materials and components that follow carefully considered design details can potentially remain useful in the materials cycle for longer periods of time, thus reducing the need for new materials and the environmental costs of resource extraction, production processes, and waste disposal.

- Assessing life cycle costs based on design service life of the structure and the building envelope can be helpful in evaluating alternative design approaches for the building.

- Some green building rating systems encourage high-performance and durable envelope design, either explicitly through the development of a Building Durability Plan, or indirectly by setting goals for energy efficiency, thermal comfort, and indoor air quality (all of which are facilitated through the design of the building envelope) [6], [7].

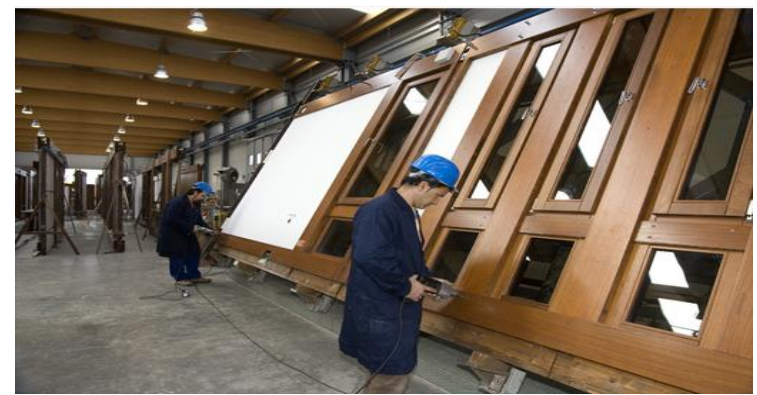

Fig. 6. Industrial assembly of technological parts to form complete sections of the building (@Pagano Engineering).

- With proper design and construction, wood-frame buildings resist damage from moisture, insects and other organisms, and provide decades of service equivalent to other building types.

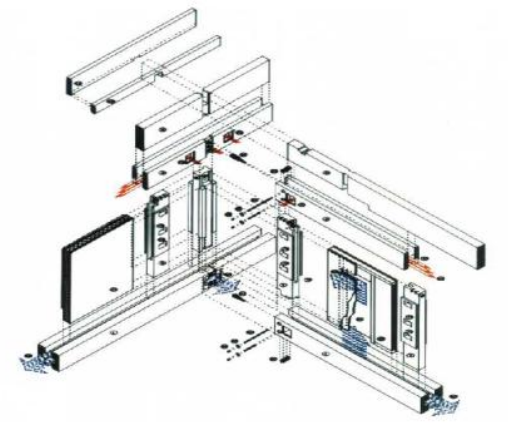

Fig. 7. Standard components of the prefabricated system (Patent @Pagano Engineering)

- Wood structures are adaptable and allow for design flexibility to meet changing needs. When they have been designed properly with local climate impacts in mind, wood buildings can last centuries. Further, when part of a well-planned regular maintenance program, wood products will last well beyond their planned service life. When it is time to refurbish, wood products can be re-used and recycled.

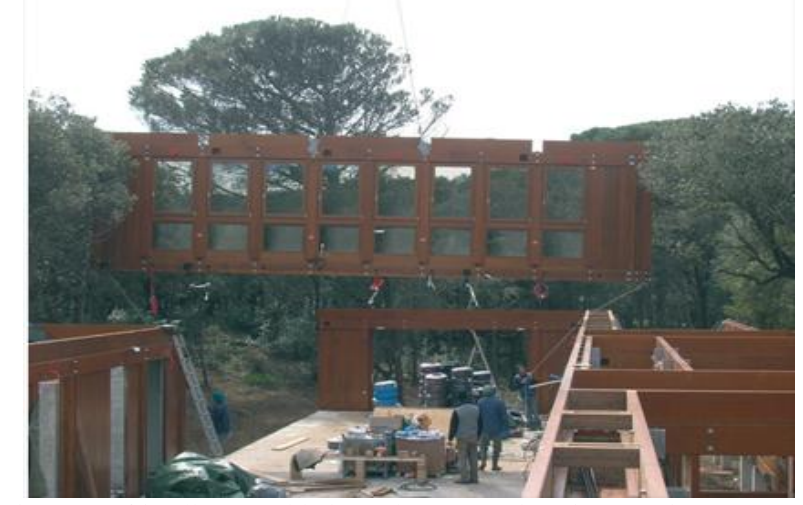

Fig. 8. Ecofriendly assembly in each construction site, Russia, (CPagano Engineering)

\section{Main ApPlications AREAS: CASE StUdies}

It is never easy to compare the costs of building with different materials and systems. So many factors are involved. For example, the relative costs of different materials change according to supply and demand, and currency fluctuations. Local conditions vary significantly. And there are many different ways to build in different materials. Building with wood could involve anything from traditional wood frame, to technologically advanced engineered systems, or even hybrid construction. And building efficiencies vary, depending on the regulatory system, scale of development, knowledge and skills, the extent of off-site construction, and how adept and experienced the construction company is at planning and managing the building process (Fig. 8).

It is important to notice, however, that wood frame systems account for around 70 per cent of residential construction in the developed world. One of the reasons for its popularity is its cost-effectiveness, which includes a much shorter construction time and less waste than other systems [8].

\section{A. Solid Wood Panels}

Solid wood panel structures provide a leading-edge alternative for six to ten-storey buildings.

Cross-laminated boards are glued together and used to build walls and joists. Panels are machined in a factory to fine tolerances by computer controlled equipment (Fig. 9). The panels arrive on site with apertures for doors and windows, and wiring and plumbing channels already prepared. The walls can be insulated to provide a high level of energy-efficiency. Superior load-carrying characteristics, including lateral stability against wind and seismic forces, as well as excellent fire safety performance, make cross laminated timbers suitable for medium and even high-rise buildings. And the amount of timber used means buildings made with solid wood panels are highly effective carbon stores. These environmentally-friendly solid wood buildings offer longer-term opportunities, particularly for high density housing requirements [9]. 

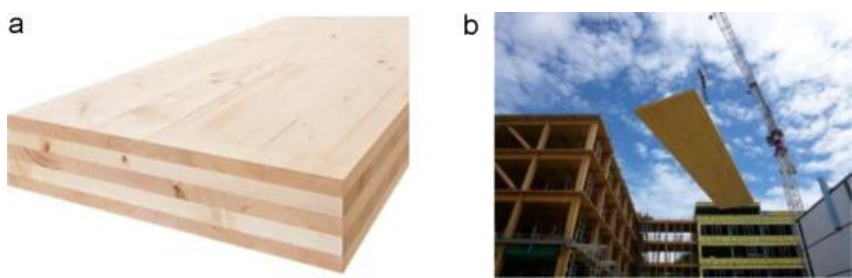

Fig. 9. ( $a$ and b) Prefabricated cross-laminated panels are engineered load-bearing jumbo panels, consisting of a series of layers, bonded together timber boards (usually spruce, larch or pine) with structural adhesives, forming a solid timber panel with each layer of the panel alternating between longitudinal and transverse lamellae. CLT panels can be up to format $3.2 \mathrm{~m} \times 16 \mathrm{~m}$ (approx. $10 \mathrm{ft} \times 45 \mathrm{ft}$ ) in size.

\section{1) Multi-storey apartment building}

The tallest built so far is a nine-storey residential building in London, England [9]. Standing nine stories in height, wood dominates from the second level onwards. The CLT-based apartment is sturdy and uses up to five layers of wood to make it more fire resistant. Wood can burn and isn't as hardy as concrete or metal. But this 29-unit structure wasn't built along the same lines as an ordinary wooden house. Thick layers of panels measuring about 6 inches in density and up to 30 feet long ensure that it is able to resist fire better. Plasterboard coverings further improve its resistance (Fig. 10).

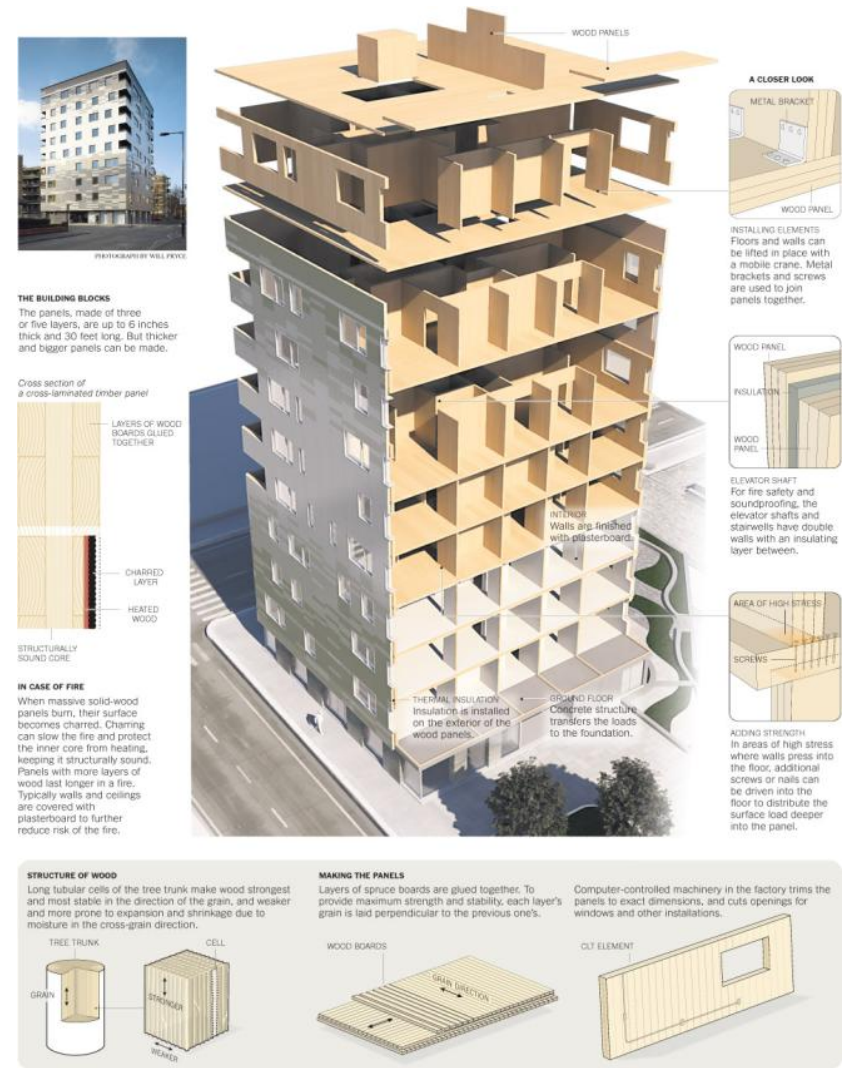

Fig. 10. Graphite Apartments, London. Constructed three years ago, the Graphite Apartments are built using engineered timber called cross-laminated timber.

The laminated spruce panels were fabricated in Austria and then shipped to London where bolting took place on-site. CLT, which resembles supersize plywood, covers all the interior walls, roof, floors, stairs and the elevator. According to Innovative Timber Systems based out of the United States, CLT is the ideal material to be used in construction (Fig. 11 and Fig. 12).

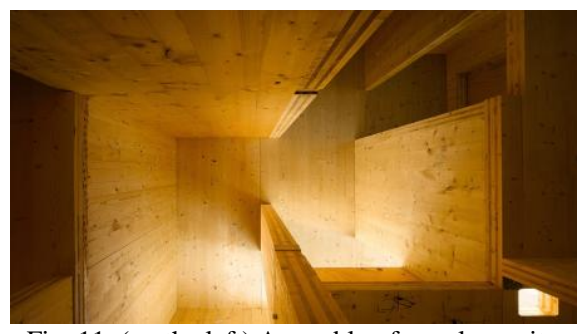

Fig. 11. (on the left) Assembly of panels on site.

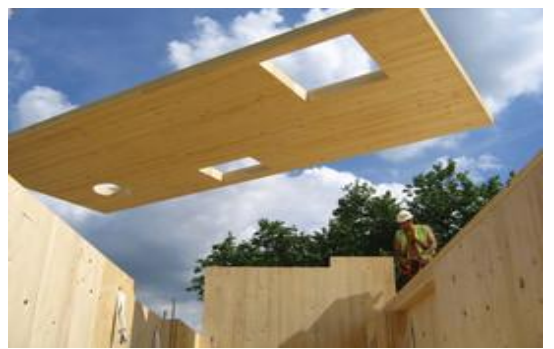

Fig. 12. (on the right) Structural elements involve many layers of spruce fused together.

\section{2) Social housing}

The residential complex Mühlweg is the result of a property developer competition tendered within the "Climate Protection Program of the City of Vienna" to point out the feasibility of the realization of multi-storey timber constructions or constructions mixed with timber through low energy architecture under the conditions of social residential building in an urban locality (Fig. 13).

The project, which was developed by Johannes Kaufmann and Hermann Kaufmann, was created not so much due to the conditions of timber construction per se, but rather was specified concerning considerations for urban development and demonstrates the various possibilities of timber as a building material in order to create high-grade living space. Based on a concept which does not try to confine it from the environment, but instead lets the 'Marchfeld' (proper name of the surrounding area) flow through the residences, three structures are placed close to the building boundary. Between the devices in the basement which are carried out in massive design and the upper floors which are carried out in supporting construction of shelves and plywood, an open courtyard area is created with differentiated ambient rooms. The structures are enclosed by highly insulated salient cladding elements made of untreated larch wood which, combined with coloured sliding shutters, create a homelike ambiance (Fig. 14). Most of the apartments face southwards or westwards and offer various living situations with a mixture of different types and sizes [10].
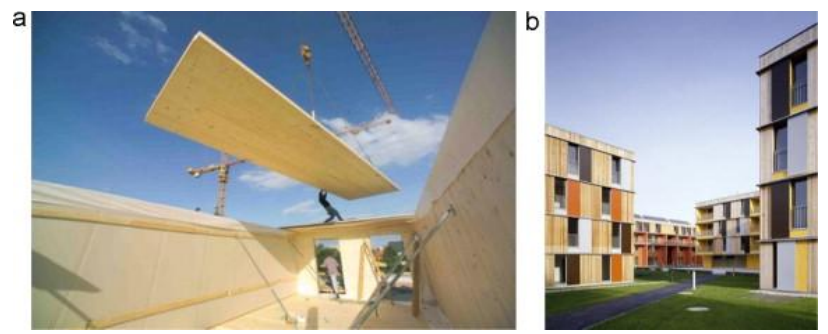

Fig. 13. (a and b) Prefabricated cross-laminated panels, up to $16 \mathrm{~m}$ in length, are delivered just in time for assembly on-site; image of a European project under construction. The 4-storey built CLT quarter in Vienna, Am

Muehlweg, shows that a very high architectural quality can be achieved even for public housing. 

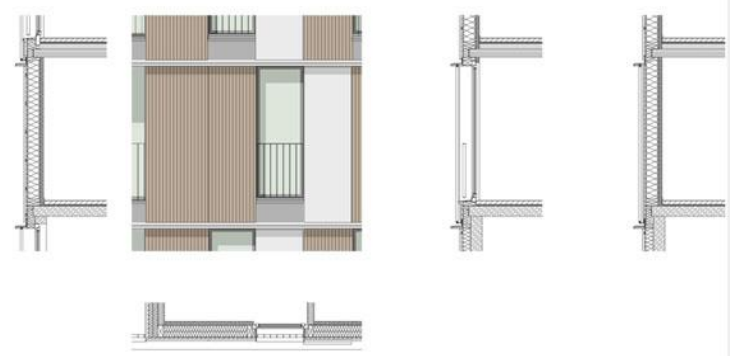

Fig. 14. Detail wooden panels envelope. CLT quarter in Vienna, Am Muehlweg,

\section{3) Emergency situation}

Years of research and building code development have proven that wood-frame and hybrid structures can meet or exceed the most demanding earthquake design requirements. Wood's high strength-to-weight ratio, high energy-absorption capacity and ductile behaviour make it a building material of choice for seismic performance. Recent earthquakes around the world have demonstrated the superior performance of modern wood structures (Fig. 15). Moreover, wood-frame construction has a proven safety and performance record for fire protection, and wood buildings can be designed to meet fire-resistance ratings. Wood is significantly less heat-conductive than steel or concrete. Heavy timbers have a particular advantage in a fire because they char on the outside while retaining strength, slowing combustion and allowing time to evacuate the building. Wood's light weight and flexibility make it also ideal for areas prone to high wind (Fig. 16; Fig. 17). First, its elastic limit and ultimate strength are higher when loads are applied for a short time, which tends to be the case in high wind events. When properly attached to lumber framing, structural panels such as plywood or oriented strand board (OSB) form solid and stable roofing, flooring and wall systems. When used to form diaphragms and shear walls, these wood products are exceptional at resisting high winds [9]-[10].
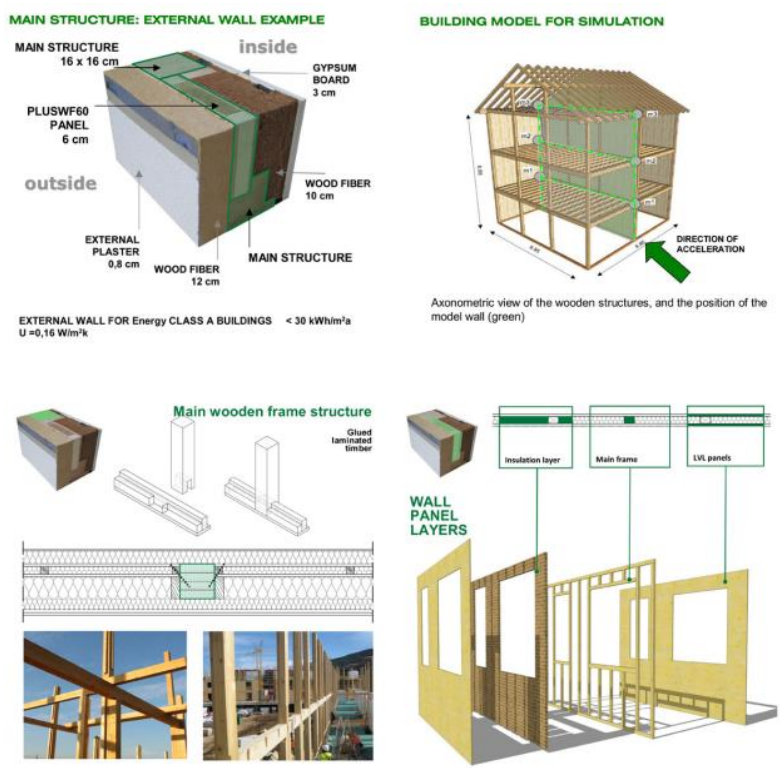

Fig. 15. 1:1 Scale model. Examples of innovative, anti-seismic and high performance wooden buildings. This is justified by the wooden structures attitude to satisfy exceptional events like earthquakes, floods, natural disasters that requires a rapid, efficient and durable restoration. (ILLE Research).

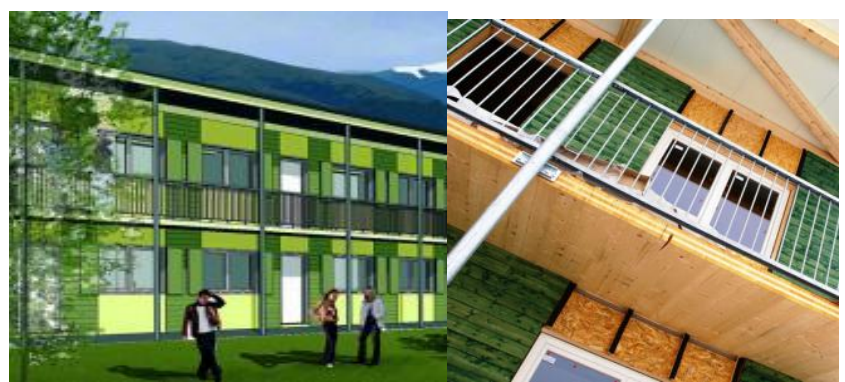

Fig. 16-17. M.A.P., the temporary living modules for reconstruction after the earthquake in Abruzzo, Italy.

\section{4) Prototypes}

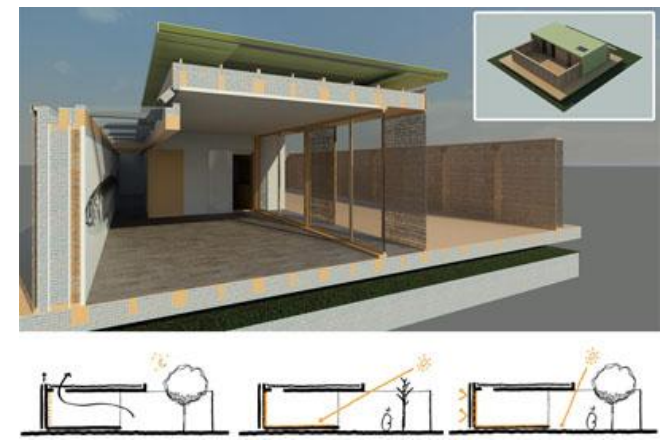

Fig. 18. Med in Italy prototype, Solar Decathlon Europe competition, 2012. Example of integration with the principles of ecological-architecture, renewable energy sources and the concept of industrialization, and assembly logic.
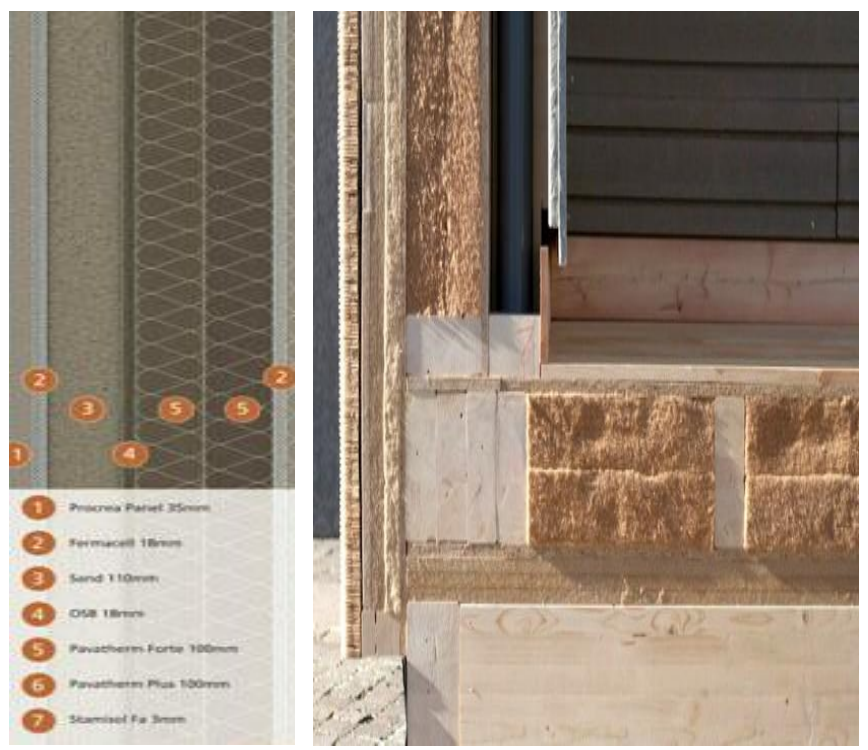

Fig. 19, 20. Wooden envelope details of Med in Italy prototype, Solar Decathlon Europe competition, 2012.

Prototypes experiments explore an innovative construction concept based on prefabricated system models that can be configured in various ways. They are achieved through: industrialization of building components production; study of the assembly logic, related with easiness of transportation, transfer to factory of construction and testing of plumbing and the majority of HVAC systems, thanks to their concentration into 3D modules to be transportated fully assembled (Fig. 18; Fig. 19; Fig. 20). Moreover, the main concept is founded on integration with renewable energy sources and on the contrast between low and high-tech construction: wood is used for the structure and cladding, and thin film photovoltaic panels are installed on the roof and along the east and west walls. The extensive use of passive strategies, including thermal mass, 
the modulation of solar gain, and the use of natural ventilation, works all together to limit the use of mechanical systems to an absolute minimum. Interesting is common threads of module-type (representing a typical floor of a miniresidential tower) that could be built in many different cities. The concept born as a response to soil consumption. This in turn led to idea of a "nanotower", with a single family home in each floor. It is sheltered by a louvered glass screen that protects against sun, rain and wind and the screen also provides a second skin, allowing the building to take advantage of either solar gain or natural ventilation depending on the situation (Fig. 21; Fig. 22). The tower is connected to the city grid, balancing electricity, mobility, heating, and cooling needs [10]-[12].
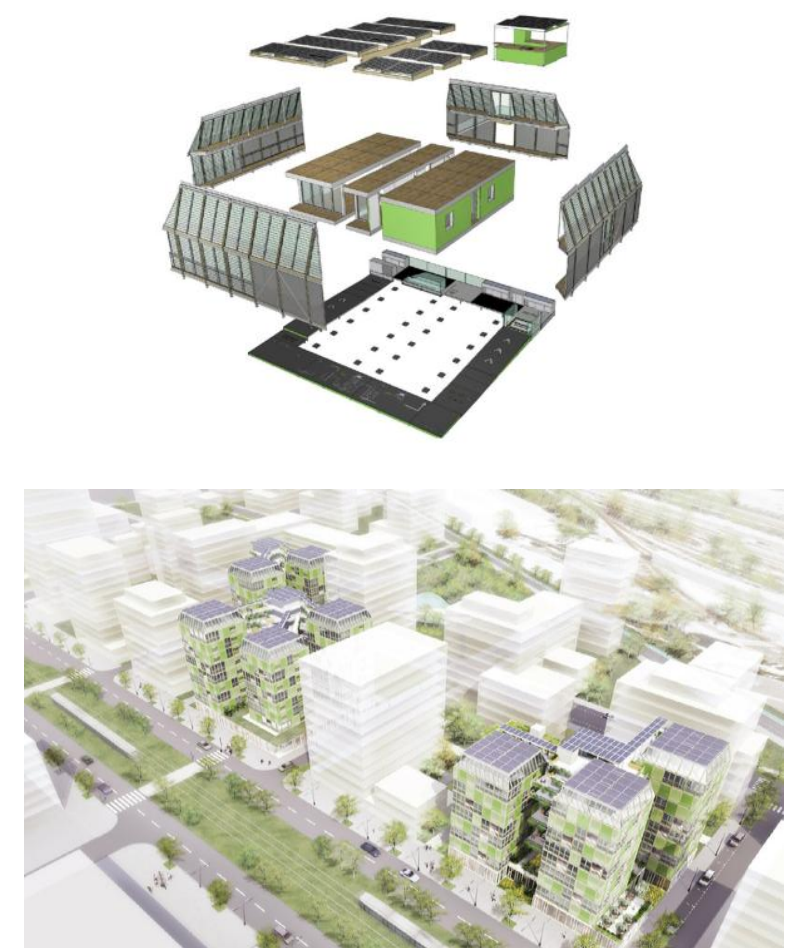

Fig. 21, 22. "Nanotower" residential prototype, Canopea house designed by Ecole Nationale Supérior d'Architecture de Grenoble (ENSAG).

\section{B. HPL Panels (High Pressure Laminates)}

The high-pressure laminate panel is known for its high quality and most common use in exterior facade applications like façade cladding in buildings. It is highly durable and is known for their excellent physical and surface properties. The HPL panels are made by infusing layers of cellulose fibers impregnated with thermosetting resins under high pressure. To create the core of the panel, sheets of cellulose fiber impregnated with phenolic resins are fused with each other at very high temperature (approximately 300 degree F) and high pressure. This procedure produces HPL panels which are homogenous, non-porous (which makes it safe from all kind of external agents like the rain, wind etc), chemically inert, and stable and has excellent mechanical properties and thus, aptly suitable for use in a number of different exterior applications. These panels are quite easy to clean with a nonabrasive household detergent. The HPL are resistant to all kinds of changes in the climate and humidity and are not adversely affected by any natural change; they are environment friendly and are produced through environment friendly techniques. They are also termite proof; this high pressure laminate with high density and homogenous structure ensures that the fasteners used (e.g. Screws) stay for a long time and so, the panels have a long life too. These panels will repel any kind of micro-organic growth. Owing to their high modulus of elasticity and tensile and flexural strength, the HPL are highly resistant to high pressure (Fig. 23; Fig. 24).

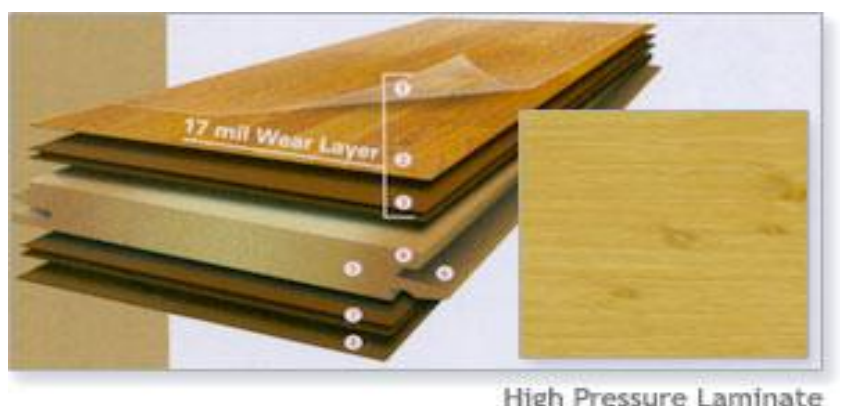

Fig. 23. Detail of HPL panel (1.High-Performance Wear Layer: 2 Decorative Sheet; 3. Phenolic Treated Kraft Sheets; 4. Penetrating Seam Sealant; 5. Water-Resistant High Density Fiberboard; 6.. Tap-N-Lock Installation Technology; 7. Phenolic Treated Kraft Sheets; 8.Balancing Layer ).

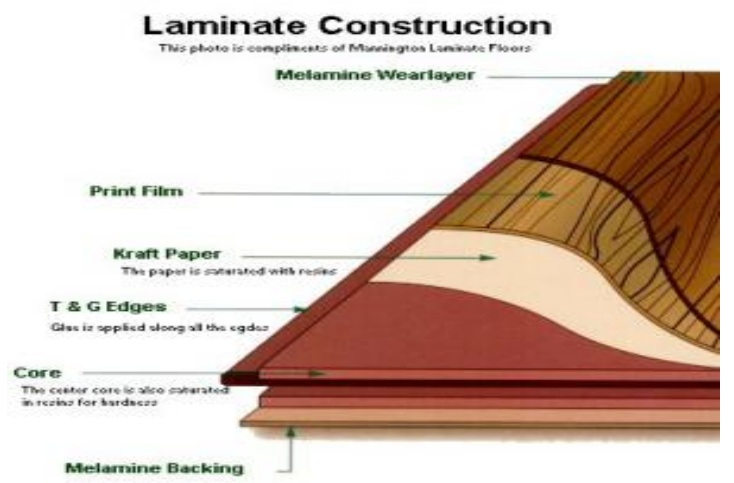

Fig. 24. Detail of HPL panels. The decorative surface of the panels is seethed with amino resins and protected with a weatherproof and lightfast outer coating.

These impressive qualities are matched by installation techniques which allow 'healthier buildings' to breathe offer particular benefits by creating a two leaf construction for the external wall, the ventilated air space between the cladding and the construction serves to maintain a healthy indoor climate. With a ventilated façade, designed to breathe, penetration of rain is minimized and condensation water is drained out through ventilation inlets and outlets. The demands of the industry for creative architecture, thermal performance, speed in erection, versatility and environmental issues have never been as great; and, they are increasing all the time. The result of these pressures has led to substantially different forms of new and exciting construction. An interesting example is the project Wohnhaus, Apartment Building in Hamburg (Fig. 25-Fig. 28). This former office building and parking house from 1974, located in the court of a large urban block, was converted into a residential house with 15 apartments. The building was cored to its shell construction and the housing technology, façade and morphology were rebuilt. The entire facade is covered with HPL panels some riveted and other glued to the support surface [13]. 

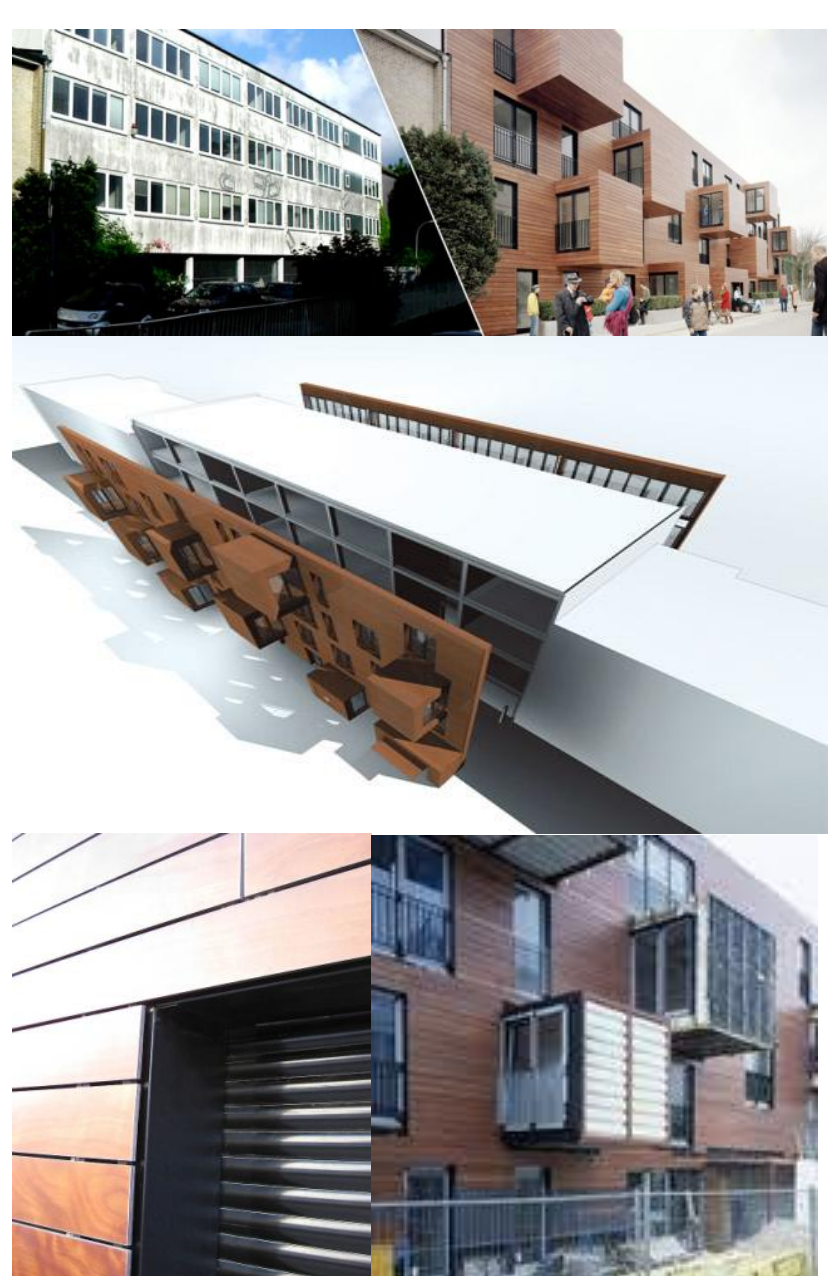

Fig. 25-28. Wohnhaus Apartment Building, Hamburg (above); details of HPL panels (below on the left) and construction site (below on the right) with installation of the ventilated facade.

\section{Wood Hybrid Construction}

Hybrid construction where wood construction is combined with concrete and/or steel construction is a promising opportunity for the future. This includes the construction of buildings which have the lower storey (or parkade) in concrete to which a light-weight energy-efficient wood super-structure can be attached (Fig. 29, Fig. 30). In Europe, wood frame buildings of up to six or seven storey high are achieved using a concrete lower storey. These hybrids are ideal for combining commercial space, such as stores and offices, in the concrete portion of the building, with housing in the wood frame part. In some settings, hybrids may be the most practical, efficient, and cost-effective option.

Fire safety codes allows the use of infill wood frame exterior walls in concrete structures up to six storey and is likely soon extend it to seven storey high for residential, offices, and certain factories and warehouses. These structures have been built cost-competitively at up to twenty storey in northern Europe for a number of years, where increasingly stringent energy-efficiency requirements are a key driver. Exterior infill walls are light, as they are designed to take only the load of their weight and the wind and seismic loads that directly affect them. They can be prefabricated in a factory or built on site and have very good insulation characteristics in relation to their thickness, providing substantially better energy performance than traditional concrete, masonry or steel construction [9]-[13].

The main benefits of exterior wood infill walls:

- Outstanding thermal properties and energy conservation.

- Reduced wall thickness maximizes usable living space by a typical 2 per cent.

- Shorter on-site construction time through pre-fabrication.

- Reduced foundation load.

- Improved seismic performance.
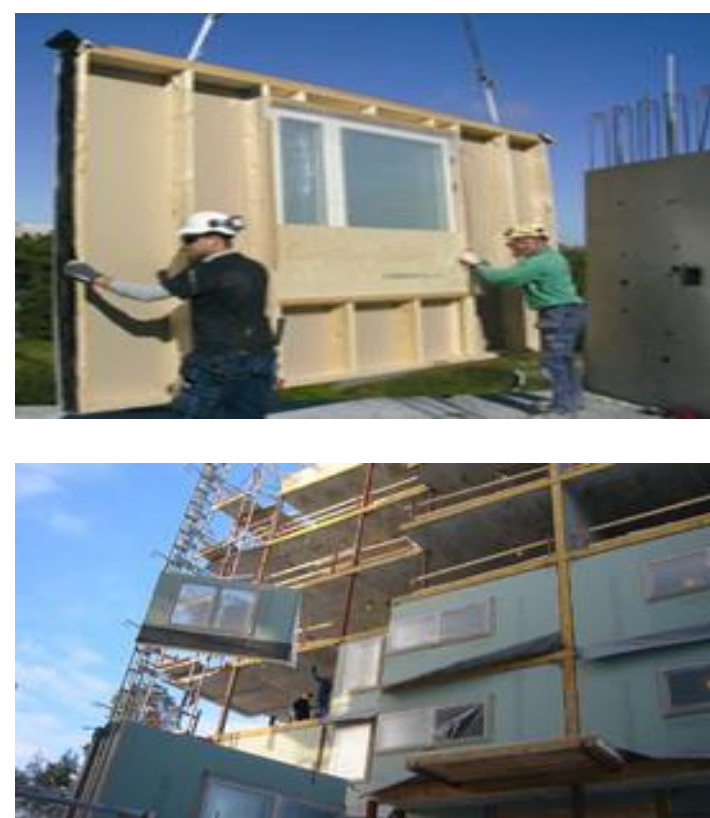

Fig. 29. Assembling prefabricated wood frame exterior infill wall panels in a multi-storey concrete structure building, Europe. They can also be designed to meet the fire and sound requirements for apartment partition walls.

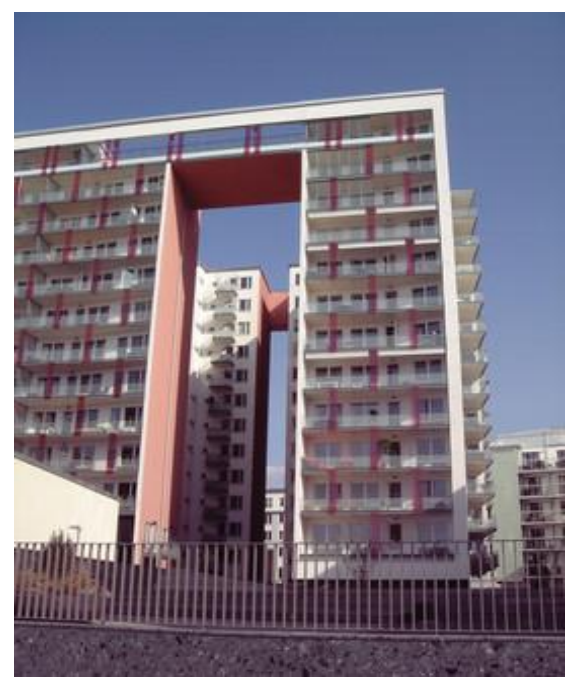

Fig. 30. High-rise apartment building using wood frame infill wall panels, Europe. Where wood frame is used for interior walls in concrete and steel structures as partitions, they provide flexibility of design, including floor layout, fire safety, sound insulation, and renovation. Wood infill partitions are non-structural, lightweight, and are suitable for a range of interior finishes.

\section{REFERENCES}

[1] R. Lancashire and L. Taylor, Innovative Timber Construction. New Ways to Achieve Energy Efficiency, TRADA Technology Ltd, High Wycombe, UK, 2012.

[2] T. Herzog, J. Natterer, R. Schweitzer, M. Volz, and W. Winter, Timber Construction Manual, Birkhauser Edition Detail, Basel, 2004.

[3] American Institute of Timber Construction, Timber Construction Manual, Hoboken Wiley, New York, 2005. 
[4] R. Lancashire and T. Lewis, Timber Frame Construction, TRADA Technology Ltd, High Wycombe, UK, 2011.

[5] M. Calkins, Materials for Sustainable Sites: A Complete Guide to the Evaluation, Selection, and Use of Sustainable Construction Materials, John Wiley \& Sons, New Jersey, 2008.

[6] G. C. Pitts, Low Energy Timber Frame Buildings: Designing for High Performance, 2nd ed. TRADA Technology Ltd, High Wycombe, UK, 2011.

[7] D. Kottas, Architecture and Construction in Wood, Barcelona, Links International, 2013.

[8] T. Hugues, L. Steiger, and J. Weber, Timber Construction: Details, Products, Case Studies, Birkhauser Edition Detail, Basel, 2004.

[9] H. König, "Lebenszyklus von Gebäuden. Vorteile nachwachsender Rohstoffe," in Proc. 2. Holzbau-Forum | Italien 2012, International Forum, Verona, 2012.

[10] "Materiali e sistemi: Strutture prefabbricate in legno, Arketipo (international review of architecture and building engineering)," Il Sole 24 ORE, Milano, no. 42, 2010.

[11] A. Ceccotti and J. W. G. Van de Kuilen, International Symposium on Advanced Timber-Composte Elements for Building: Design, Construction Manifacturing and Fire Safety, CNR-Ivalsa, Firenze, 2004.

[12] Solar Decathlon 2012, "Innovation and ideas in the 18 solar houses, Arketipo (international review of architecture and building engineering)," Il Sole 24 ORE, Milano, no. 67, 2012.

[13] T. Ferrante, Legno E Innovazione, Alinea, Firenze, 2008.

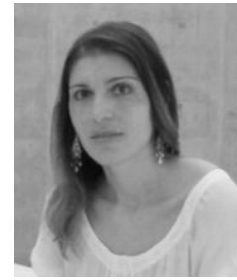

Fabiana Cambiaso was born in Rome. She is an architect and Civil engineer. She graduated in Architecture at Sapienza University of Rome, Italy in 2008. She obtained the M.Sc. degree as a Civil engineer and 2nd level University master degree in "Ecological Architecture and environmentally Sustainable Technologies" with Honours in 2010 She obtained the Ph.D. in Environmental Design at DATA Department. All from Sapienza University of Rome. She is a researcher in the field of innovative materials and sustainable technologies for high performance building's envelope, energy saving and thermal comfort in building design.

She worked for Rome Municipality about the project "Retrofitting of an existing building in S.Lorenzo" (historical centre of Rome) presented in a lecturer in 4th International Congress Bauhaus.SOLAR 2011, at Erfurt, Germany. About those topics, she is author of many articles.

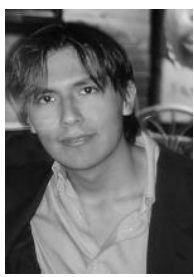

Matteo Varioli Pietrasanta was born in La Paz, Bolivia. He is an architect. He graduated from Sapienza University of Rome, Italy in 2008 with a degree in Architecture. In 2011, from the same university, he completed a 2nd level University master degree in "Ecological Architecture and environmentally Sustainable Technologies".

He was offered an internship on Zaha Hadid's MAXXI (National Museum of the 21st Century Arts)

construction site.

He then worked for Rome Municipality where he was in charge of the retrofitting project of a school building in a city sub-urban area. Since 2011 he is an architect at Pagano Engineering (Rome), a company specialized in wooden prefabricated buildings with worldwide customers. 